\title{
Gradation Design and Performance Evaluation of High Viscosity Asphalt Mixtures
}

\author{
Xudong Hu, ${ }^{1,2}$ Sheng Li $\left(\mathbb{D},{ }^{3}\right.$ Hui Yao $\left(\mathbb{D},{ }^{4}\right.$ Hui Wang, ${ }^{3}$ Mei Xu, ${ }^{4}$ Dandan Cao, ${ }^{4}$ \\ Mohd Rosli Mohd Hasan, ${ }^{5}$ Cong Duan, ${ }^{6}$ and Ran Zhang ${ }^{7}$ \\ ${ }^{1}$ School of Civil Engineering, Central South University, Changsha 410072, China \\ ${ }^{2}$ Department of Transportation Engineering, National University of Defense Technology, Changsha 410072, China \\ ${ }^{3}$ School of Transportation Engineering, Changsha University of Science and Technology, Changsha 410114, China \\ ${ }^{4}$ Beijing Key Laboratory of Traffic Engineering, College of Metropolitan Transportation, Beijing University of Technology, No. 100, \\ Pingleyuan, Chaoyang, Beijing 100124, China \\ ${ }^{5}$ School of Civil Engineering, Universiti Sains Malaysia, Nibong Tebal, George Town, Penang 14300, Malaysia \\ ${ }^{6}$ National Land Resources Engineering Institute, Lianhua Campus, Kunming University of Science and Technology, \\ Kunming 650093, China \\ ${ }^{7}$ School of Highway, Chang'an University, Xi'an 710064, China \\ Correspondence should be addressed to Sheng Li; lishengttt@163.com and Hui Yao; huiyao@mtu.edu
}

Received 21 October 2019; Revised 5 November 2020; Accepted 9 November 2020; Published 30 December 2020

Academic Editor: Chao Wu

Copyright (C) 2020 Xudong Hu et al. This is an open access article distributed under the Creative Commons Attribution License, which permits unrestricted use, distribution, and reproduction in any medium, provided the original work is properly cited.

\begin{abstract}
The property of asphalt binder plays an important role in the performance of asphalt mixture. The natural rubber additive (NRA) was recommended as a modifier in the preparation of high viscosity asphalt (HVA) binder. Then, the gradation named LASTIKA13 was adopted to design the high viscosity asphalt mixture (HVAM) according to the orthogonal test analysis and the optimized gradation. The performance of the proposed HVAM was evaluated through a series tests including the permanent deformation at high temperature, moisture stability, low-temperature cracks, and bending fatigue test. The results indicate that the proposed modified asphalt binder shows a comparable property with the conventional modified asphalt binder. The proposed HVAM with the NRA modifier has a superior performance to other conventional mixtures in the temperature susceptibility and resistance to moisture damage. Furthermore, the proposed HVAM was less sensitive to the temperature change and has good performance in terms of resistance to low-temperature cracks, bonding characteristics, and fatigue behaviors.
\end{abstract}

\section{Introduction}

The high viscosity asphalt (HVA) binder is well known for its excellent characteristics such as high viscosity, low penetration, and high softening point. Consequently, the high viscosity asphalt mixtures (HVAM) show a superior performance in high-temperature stability, and resistance to moisture damage of asphalt mixtures $[1,2]$. The styrene-butadiene-styrene (SBS) modified asphalt mixture is one of the mostly used mixtures in the pavement construction and industry. Due to the superior performance, it is also widely adopted as the drainage asphalt pavement and wear course on the bridge deck [3-5]. The HVAM is a patented technology that has been widely used in Japan, Europe, and the United States, which is often unaffordable in other countries due to its high expense as compared to other additives, and it restricts the application of HVA $[6,7]$.

Various additions, such as nanomaterials [8-10], crumb rubber [11-13], and waste materials [14, 15], have been used as modifiers into neat asphalt binder to improve the performance of neat asphalt binder for specific purposes. Previous studies have documented that the nanomaterials, for instance, nanoclay [16], nanosilica [10], nanohydrated lime [17], and carbon nanotube [18], can efficiently enhance the viscosity and high-temperature performance of neat asphalt binder. These materials and modified asphalt binders 
were observed by the microscopes, and the microstructures of the modified asphalt binders were analyzed. These materials essentially improved the bonding strength between the asphalt binder and aggregates. The use of composites in the asphalt binder is also a hot direction to improve the quality of asphalt binders and mixtures. The combination of castor beans-based bioasphalt and European rock asphalt at a certain ratio was used for the modification of asphalt binders and mixtures. The use of rock asphalt in the bioasphalt overcomes the adverse effect of bioasphalt, and the high-temperature performance of modified asphalt binder improved, as well as other specific properties [19]. The polymethyl methacrylate (PMMA) and graphene nanoparticles (GNPs) composite (PMMA-GNPs) was synthesized to fabricate the PMMA-GNPs/SBS modified asphalt binder with the microwave heating. The mechanical tests were used to describe the modification mechanism [20]. The crumb rubber (CR) and SBS were mixed as the composite to modify the asphalt binder. Different particle sizes of $C R$ were investigated to analyze the influence on the performance of asphalt binders and mixtures, as well as the SBS with different molecular structures. This combination improved the cost-effectiveness of asphalt binders [21]. The polyurethane (PU) and rock asphalt (RA) were mixed into the asphalt to make the composite asphalt binder. The following mechanical tests were used to characterize the properties of modified asphalt binders with different PU and RA contents including the dynamic shear rheology (DSR), bending beam rheology (BBR), X-ray diffraction (XRD), Fourier transform infrared spectroscopy (FTIR), scanning electron microscopy (SEM), differential scanning calorimetry (DSC), and thermal gravity (TG) [22]. Two additives, naphthenic oil and NanoMontmorillonite, were added into the SBS modified asphalt binder, and this process overcomes the drawback of each single additive modified asphalt binder at the optimum dosage [23]. The microalgae biodiesel (MB) was used to mix with the presynthesized crumb rubber-SBS (CR/SBS) to prepare MB-CR-SBS composite asphalt binder. Dynamic shear rheometer and multiple stress creep recovery were employed to characterize the asphalt binder, and the MBCR-SBS modified asphalt binder exhibited a large complex modulus, a small phase angle, and a high average recovery rate. The mechanism of MB-CR-SBS modified asphalt binder was revealed and elaborated through the result analysis from Fourier transform infrared spectroscopy and proton nuclear magnetic resonance spectroscopy [24]. The use of polyphosphoric acid (PPA) in the CR modified asphalt binder helps the storage stability of CR and rheological behaviors. The attenuated total reflection Fourier transform infrared spectrometer (ATR-FTIR) was used to characterize the PPA/CR combination with the chemical and physical process [25].

The natural rubber additive (NRA) from Indonesia has been used as a modifier to improve the performance of asphalt binders and mixtures, and an expressway with the overlay of NRA modified asphalt mixture was constructed in Jakarta. $\mathrm{Hu}$ et al. introduced the application of NRA modified asphalt mixtures in China, and the uniform experiments and orthogonal tests were analyzed [26]. Wang concluded that the NRA modified asphalt binder is applicable to small- and medium-sized construction projects. The NRA asphalt mixtures were paved on "Tanguang Road," Nanan district, Chongqing, in 2010. The excellent pavement performance was demonstrated [27]. Wang et al. tested the NRA modified asphalt binders with various proportions to determine the optimum asphalt content of NRA modified asphalt binder [28]. Previous studies denoted that the NRA modified asphalt binder shows low penetration and high viscosity [29]; however, few studies have focused on the gradation design of modified asphalt mixtures.

A high viscosity asphalt mixture with the NRA modifier was prepared to understand the modification effect, and the properties of asphalt binders and mixtures were evaluated to simulate the field performance. In order to better understand these modified asphalt binders and mixtures, the optimum proportion of NRA was determined to produce the HVA. The high-temperature performance and fatigue performance of HVA were evaluated to understand the modification mechanism. Then, the HVAM was prepared with the special LASTIKA-13 gradation. The mixture performance was characterized including the Marshall stability, high- and low-temperature performance, moisture susceptibility, and fatigue performance to understand if the high viscosity asphalt binder and mixture can be of potential interest for the practical application in highway construction.

\section{Materials}

2.1. Neat Asphalt Binder. The asphalt binder used in this study could be classified as 70 \# in China penetration grading system or PG (Performance Grade) 64-22 based on SUPERPAVE system. The characteristics of the neat asphalt binder 70\# were shown in Table 1 . All tests were conducted in accordance with the China specification JTG E20-2011, and the results show that the property of neat asphalt binder meets the requirements of test standards.

2.2. Natural Rubber Additive (NRA). The NRA is a combination of asphalt binder and natural rubber with a certain ratio from the company managers. The NRA was mixed by one hour with the combination through the high shear mixer with $2000 \mathrm{rpm}$ and the shear temperature should be carefully selected based on the viscosity result of neat asphalt binder used in NRA. The mixing temperature of modified asphalt binder is $165^{\circ} \mathrm{C}$ for the material preparation, and the NRA has a high viscosity and an excellent high-temperature stability. The NRA modified asphalt binders were prepared by mixing the NRA modifier with asphalt binders, and a high viscosity asphalt binder was formed. The performance of the modified high viscosity asphalt binder was evaluated in accordance with the China specifications, and the results are shown in Table 2.

It could be seen from Table 2 that, at $25^{\circ} \mathrm{C}$, the penetration of NRA modified asphalt binder was smaller than that of neat asphalt binder, and the softening point and the viscosity were higher than those of neat asphalt binder. The NRA modified asphalt shows high viscosity and low heat 
TABLE 1: Test indices of 70\# neat asphalt binder.

\begin{tabular}{lcccc}
\hline Parameters & Unit & Result & Criteria & Method [23] \\
\hline Penetration $\left(25^{\circ} \mathrm{C} 100 \mathrm{~g} 5 \mathrm{~s}\right)$ & $0.1 \mathrm{~mm}$ & 71 & $60-80$ & T0604 \\
Penetration index & - & -1.28 & $-1.5-+1.0$ & T0604 \\
Softening point (ring \& ball test) & ${ }^{\circ} \mathrm{C}$ & 47 & $\geq 46$ & T0606 \\
Ductility at $15^{\circ} \mathrm{C}$ & $\mathrm{cm}$ & 31 & $\geq 20$ & $\mathrm{~T} 0605$ \\
Ductility at $25^{\circ} \mathrm{C}$ & $\mathrm{cm}$ & $>100$ & $>100$ & $\mathrm{~T} 0605$ \\
Kinematic viscosity $\left(60^{\circ} \mathrm{C}\right)$ & $\mathrm{Pa} . \mathrm{s}$ & 210 & $\geq 180$ & $\mathrm{~T} 0625$ \\
Solubility & $\%$ & 99.7 & $\geq 99.5$ & $\mathrm{~T} 0607$ \\
Density & $\mathrm{g} / \mathrm{cm}^{3}$ & 1.03 & Actual measurement & T0603 \\
\hline
\end{tabular}

TABle 2: Properties of NRA modifiers.

\begin{tabular}{lccc}
\hline Parameters & Unit & Result & Technical requirement provided by indonesian manufacturers \\
\hline Penetration $\left(25^{\circ} \mathrm{C} 100 \mathrm{~g} 5 \mathrm{~s}\right)$ & $0.1 \mathrm{~mm}$ & 42 & $40-50$ \\
Ductility $\left(5 \mathrm{~cm} / \mathrm{min} 15^{\circ} \mathrm{C}\right)$ & $\mathrm{cm}$ & 23 & - \\
Softening point (ring \& ball test) & ${ }^{\circ} \mathrm{C}$ & 84.5 & $>80$ \\
Elasticity recovery rate $\left(5 \mathrm{~cm} / \mathrm{min}, 25^{\circ} \mathrm{C}\right)$ & $\%$ & 62.7 & $>30$ \\
Kinematic viscosity $\left(60^{\circ} \mathrm{C}\right)$ & $\mathrm{Pa} . \mathrm{s}$ & 22136 & $>20000$ \\
\hline
\end{tabular}

resistance, indicating that it is more suitable for the southern region in China, in which the field (or surface) temperature could be more than $60^{\circ} \mathrm{C}$.

2.3. High Viscosity Asphalt (HVA) Binder. The high viscosity asphalt (HVA) binder was produced through mixing the neat asphalt binder and NRA modifiers with different proportions. A trial test in the laboratory was conducted, and three proportions $(10 \%, 15 \%$, and $20 \%)$ were selected for NRA modified asphalt binder. The basic performance of HVA was evaluated in accordance with China Specifications JTG E20-2011, and the test results are listed in Table 3.

It can be shown from Table 3 that the penetration, ductility, softening point, and elastic recovery of HVAs were comparable with the SBS-modified (SM) asphalt binder when the percentage of NRA is $15 \%$, and the viscosity meets the requirements of heavy traffic paving asphalt binder in China. The SBS modifier used in this project is a commercially available product, and the properties of SBS could be found in reference [30]. The standard criteria were selected in accordance with the China specifications.

2.4. Aggregate. The limestone aggregate was provided by a local quarry in Hunan Province, China, which was composed of four varieties of unbound aggregate material. The ranges of the particle size are $9.5-13.2 \mathrm{~mm}, 4.75-9.5 \mathrm{~mm}$, $2.36-4.75 \mathrm{~mm}$, and $0-2.36 \mathrm{~mm}$, respectively. The aggregate with the particle size beyond $4.75 \mathrm{~mm}$ could be categorized as coarse aggregate in accordance with China specifications JTG E42-2005 "Test methods of aggregate for highway engineering." Previously studies documented that the properties of aggregates and gradation are greatly related to the performance of asphalt mixture, and the physical and mechanical properties of various aggregates should be satisfied with the requirements of design standards as well as the needle-shape and flake-shape particle concentration. The technical requirements and the test results of both coarse and fine aggregates are listed in Tables 4 and 5. In addition, the test results and quality requirements of the mineral filler are presented in Table 6 . The test results demonstrated that the physical and mechanic properties of limestone aggregate and filler material used satisfy the requirement in accordance with the specification.

\section{Gradation Design of High Viscosity Asphalt Mixture}

The recommended gradation of aggregates was used, and the properties of HVAM were assessed from different aspects including high- and low-temperature performance, as well as the fatigue life and moisture susceptibility based on the conventional mixes AC-13. The nominal maximum aggregate size was $13 \mathrm{~mm}$ for this project. The orthogonal test method proposed by Rao [31] for multiple factors design was adopted in the gradation design. The orthogonal test method potentially decreased the experiment numbers during the consideration of different factor. Based on the current experience and data support, the percentage passing the sieve size $(2.36 \mathrm{~mm})$ in the LASTIKA-13 gradation is $18 \%-34 \%$, and this LASTIKA-13 gradation was introduced and proposed by the Indonesia company. Meanwhile, the passing percentage at $4.75 \mathrm{~mm}$ should be approximately $34 \%-50 \%$ to avoid the cross between the lower limit at $4.75 \mathrm{~mm}$ and the upper limit at $2.36 \mathrm{~mm}$. Then, the passing rates of $13.2 \mathrm{~mm}$, $9.5 \mathrm{~mm}, 4.75 \mathrm{~mm}$, and $0.075 \mathrm{~mm}$ were roughly $88 \%-100 \%$, $48 \%-78 \%, 34 \%-50 \%$, and $4 \%-10 \%$, respectively. The final factors and levels detected and determined via an orthogonal test of LASTIKA-13 gradation are shown in Table 7 . Therefore, we choose an orthogonal table as the scheme table of LASTIKA-13 gradation and arrange the factors and levels. The aggregate was classified into various groups based on its size range, and the gradation was generated using different portions of various groups. The orthogonal experimental gradation is presented in Table 8 . 
TABLE 3: Performance of high viscosity asphalt binder.

\begin{tabular}{|c|c|c|c|c|c|}
\hline \multirow{2}{*}{ Parameters } & \multirow{2}{*}{ Unit } & \multicolumn{3}{|c|}{ HVA with NRA modifier } & \multirow{2}{*}{ Standard criteria [23] } \\
\hline & & $10 \%$ & $15 \%$ & $20 \%$ & \\
\hline Penetration $\left(100 \mathrm{~g}, 5 \mathrm{~s}, 25^{\circ} \mathrm{C}\right)$ & $0.1 \mathrm{~mm}$ & 66 & 64 & 62 & 30-60 (SM asphalt) \\
\hline Ductility $\left(5 \mathrm{~cm} / \mathrm{min}, 15^{\circ} \mathrm{C}\right)$ & $\mathrm{cm}$ & 6.4 & 7.6 & 8.1 & $\nless 20$ (SM asphalt) \\
\hline Softening point & ${ }^{\circ} \mathrm{C}$ & 51.0 & 68.5 & 74.5 & $\Varangle 60$ (SM asphalt) \\
\hline Mass loss after RFOT & $\%$ & 0.02 & 0.05 & 0.02 & - \\
\hline Penetration ratio after $\mathrm{RFOT}\left(25^{\circ} \mathrm{C}\right)$ & $\%$ & 78.2 & 78.8 & 86 & - \\
\hline Viscosity $\left(60^{\circ} \mathrm{C}, 27,100 \mathrm{RPM}\right)$ & $\mathrm{Pa} \cdot \mathrm{s}$ & 2,617 & 3,050 & 3,393 & $>3,000$ (HVA of Japan) \\
\hline Elastically recovery rate $\left(25^{\circ} \mathrm{C}\right)$ & $\%$ & 19.0 & 29.0 & 34.0 & $\nless 75$ (SM asphalt) \\
\hline
\end{tabular}

TABle 4: Properties of aggregates.

\begin{tabular}{|c|c|c|c|c|}
\hline Parameters & & Unit & Test results & Technical requirements \\
\hline Crushing value & & $\%$ & 18.9 & $\leq 26$ \\
\hline Los Angeles abrasion loss & & $\%$ & 15.9 & $\leq 28$ \\
\hline \multirow{4}{*}{ Apparent specific gravity } & $9.5 \mathrm{~mm}-13.2 \mathrm{~mm}$ & & 2.771 & \\
\hline & $4.75 \mathrm{~mm}-9.5 \mathrm{~mm}$ & - & 2.776 & $\geq 2.6$ \\
\hline & $2.36 \mathrm{~mm}-4.75 \mathrm{~mm}$ & & 2.775 & \\
\hline & $9.5 \mathrm{~mm}-13.2 \mathrm{~mm}$ & & 2.741 & \\
\hline \multirow[t]{3}{*}{ Bulk specific gravity } & $4.75 \mathrm{~mm}-9.5 \mathrm{~mm}$ & - & 2.736 & - \\
\hline & $2.36 \mathrm{~mm}-4.75 \mathrm{~mm}$ & & 2.731 & \\
\hline & $9.5 \mathrm{~mm}-13.2 \mathrm{~mm}$ & & 0.41 & \\
\hline \multirow[t]{2}{*}{ Moisture absorption } & $4.75 \mathrm{~mm}-9.5 \mathrm{~mm}$ & $\%$ & 0.51 & $\leq 2.0$ \\
\hline & $2.36 \mathrm{~mm}-4.75 \mathrm{~mm}$ & & 0.60 & \\
\hline \multirow{2}{*}{ Particle concentration of needle-shaped and flake-shaped } & $9.5 \mathrm{~mm}-13.2 \mathrm{~mm}$ & $\%$ & 5.5 & $\leq 10$ \\
\hline & $4.75 \mathrm{~mm}-9.5 \mathrm{~mm}$ & $\%$ & 13.7 & $\leq 15$ \\
\hline Solidity & & $\%$ & 0.82 & $\leq 12$ \\
\hline
\end{tabular}

Table 5: Test Results of fine aggregates.

\begin{tabular}{|c|c|c|c|c|c|c|c|}
\hline Item & $\begin{array}{l}\text { Apparent relative } \\
\text { density }\left(\mathrm{t} / \mathrm{m}^{3}\right)\end{array}$ & $\begin{array}{l}\text { Bulk volume } \\
\text { relative density }\end{array}$ & $\begin{array}{c}\text { Moisture } \\
\text { absorption (\%) }\end{array}$ & $\begin{array}{c}\text { Sand equivalent } \\
(\%)\end{array}$ & $\begin{array}{c}\text { Angularity } \\
(\mathrm{s})\end{array}$ & $\begin{array}{c}\text { Silt content } \\
(\%)\end{array}$ & $\begin{array}{c}\text { Solidity } \\
(\%)\end{array}$ \\
\hline Test results & 2.779 & 2.730 & 0.65 & 63 & 36 & 2.7 & 2.14 \\
\hline Requirements & $\geq 2.5$ & - & $\leq 2$ & $\geq 60$ & $\geq 30$ & $\leq 3$ & $\leq 12$ \\
\hline
\end{tabular}

TABle 6: Properties of mineral filler.

\begin{tabular}{|c|c|c|c|c|c|c|c|}
\hline Index & $\begin{array}{l}\text { Apparent density } \\
\qquad\left(\mathrm{t} / \mathrm{m}^{3}\right)\end{array}$ & $\begin{array}{c}\text { Moisture content } \\
(\%)\end{array}$ & $\begin{array}{c}\text { Hydrophilic coefficient } \\
\text { (\%) }\end{array}$ & Appearance & & $\begin{array}{r}\text { ranularity } \\
(<0.6 \mathrm{~m} \\
<0.15 \mathrm{~m} \\
<0.075 \mathrm{n}\end{array}$ & $\begin{array}{l}\text { scope } \\
\text { m, } \\
\text { m, } \\
\text { m) }\end{array}$ \\
\hline Test results & 2.737 & 0.28 & 0.71 & \multirow{2}{*}{$\begin{array}{l}\text { Qualification } \\
\text { No-aggregate } \\
\text { agglomerate }\end{array}$} & 100 & 96.7 & 83.7 \\
\hline Requirements & $\geq 2.5$ & $\leq 1$ & $<1$ & & 100 & $90-100$ & $75-100$ \\
\hline
\end{tabular}

TABLE 7: Factors and levels of orthogonal test of LASTIKA-13.

\begin{tabular}{|c|c|c|c|c|c|}
\hline \multirow{2}{*}{ Factors levels } & \multicolumn{5}{|c|}{ Sieve size $(\mathrm{mm})$ and passing percentage $(\%)$} \\
\hline & $13.2\left(N_{1}\right)$ & $9.5\left(N_{2}\right)$ & $4.75\left(N_{3}\right)$ & $2.36\left(N_{4}\right)$ & $0.075\left(N_{5}\right)$ \\
\hline 1 & 88 & 48 & 34 & 18 & 4 \\
\hline 2 & 92 & 58 & 39 & 23 & 6 \\
\hline 3 & 96 & 68 & 44 & 28 & 8 \\
\hline 4 & 100 & 78 & 50 & 34 & 10 \\
\hline
\end{tabular}


TABLE 8: Scheme of LASTIKA-13 gradation orthogonal Test.

\begin{tabular}{lcccccccccc}
\hline \multirow{2}{*}{ Gradation } & \multicolumn{10}{c}{ Sieve size $(\mathrm{mm})$} \\
& 16.0 & 13.2 & 9.5 & 4.75 & 2.36 & 1.18 & 0.6 & 0.3 & 0.15 & 0.075 \\
\hline 1 & 100 & 88 & 48 & 34 & 18 & 15 & 10 & 7 & 5 & 4 \\
2 & 100 & 88 & 58 & 39 & 23 & 18 & 13 & 10 & 8 & 6 \\
3 & 100 & 88 & 68 & 44 & 28 & 21 & 16 & 13 & 11 & 8 \\
4 & 100 & 88 & 78 & 50 & 34 & 24 & 20 & 16 & 15 & 10 \\
5 & 100 & 92 & 48 & 39 & 28 & 15 & 13 & 13 & 15 & 10 \\
6 & 100 & 92 & 58 & 34 & 34 & 18 & 10 & 16 & 11 & 8 \\
7 & 100 & 92 & 68 & 50 & 18 & 21 & 20 & 7 & 8 & 6 \\
8 & 100 & 92 & 78 & 44 & 23 & 24 & 16 & 10 & 5 & 4 \\
9 & 100 & 96 & 48 & 44 & 34 & 15 & 16 & 16 & 8 & 6 \\
10 & 100 & 96 & 58 & 50 & 28 & 18 & 20 & 13 & 5 & 4 \\
11 & 100 & 96 & 68 & 34 & 23 & 21 & 10 & 10 & 15 & 10 \\
12 & 100 & 96 & 78 & 39 & 18 & 24 & 13 & 7 & 11 & 8 \\
13 & 100 & 100 & 48 & 50 & 23 & 15 & 20 & 10 & 11 & 8 \\
14 & 100 & 100 & 58 & 44 & 18 & 18 & 16 & 7 & 15 & 10 \\
15 & 100 & 100 & 68 & 39 & 34 & 21 & 13 & 16 & 5 & 4 \\
16 & 100 & 100 & 78 & 34 & 28 & 24 & 10 & 13 & 8 & 6 \\
\hline
\end{tabular}

\section{Results and Analysis of Orthogonal Tests}

The asphalt content of $4.8 \%$ was used to perform the experiments based on the Marshall mixture design method with the above-mentioned gradations for asphalt mixtures. All samples were compacted at $160^{\circ} \mathrm{C}$ with 75 hits for each side prior to obtain the percentage of air void (VV), voids in mineral aggregate (VMA), the percentage of air voids filled with asphalt (VFA), and Marshall Stability (MS). These test results are listed in Table 9. The orthogonal experimental method was used to analyze the range of each volume parameter and mechanical behavior. The results are shown in Table 10 and Figure 1.

The range analysis appears to be a simple, understandable and intuitive method of the orthogonal test [29]. During the orthogonal experimental assessment, through range analysis, the major and minor factors, as well as the optimal levels, are ranked and chosen to select the optimal combination. Overall, the LASTIKA-13 grading was adopted to conduct further range analysis on MS and each volume index (VV and VMA).

The Marshall Stability analysis results presented in Figure 1(a) indicate that the influence sequence of each Marshall factor from high to low is as follows: $2.36 \mathrm{~mm}$, $13.2 \mathrm{~mm}, 0.075 \mathrm{~mm}, 4.75 \mathrm{~mm}$, and $9.5 \mathrm{~mm}$. The $\mathrm{K}$ value of each factor level varies from one to another. Referring to the optimal level of combination with the highest stability, the passing ratios of $13.2 \mathrm{~mm}, 9.5 \mathrm{~mm}, 4.75 \mathrm{~mm}, 2.36 \mathrm{~mm}$, and $0.075 \mathrm{~mm}$ are $92 \%, 78 \%, 44 \%, 23 \%$, and $10 \%$, respectively. Figure 1(b) presents that the influence of each factor varies based on the penetration-influence sequence from high to low, $2.36 \mathrm{~mm}, 13.2 \mathrm{~mm}, 4.75 \mathrm{~mm}, 0.075 \mathrm{~mm}$, and $9.5 \mathrm{~mm}$. The medium value of $\mathrm{VV}$ between $3 \%$ and $5 \%$, which is regulated and specified as the designed $\mathrm{VV}$, is considered to obtain the optimal level of each sieve. Overall, the results indicate that the passing of the $13.2 \mathrm{~mm}$ is $96 \%$, followed by $9.5 \mathrm{~mm}, 4.75 \mathrm{~mm}, 2.36 \mathrm{~mm}$, and $0.075 \mathrm{~mm}$ with $48 \%, 50 \%$, $28 \%$, and $8 \%$, respectively. Figure 1(c) summarizes the VMA data, and the results indicate that the influence sequence of each factor from high to low is $2.36 \mathrm{~mm}, 13.2 \mathrm{~mm}$,
TABLE 9: Marshall test results of LASTIKA-13 orthogonal schemes.

\begin{tabular}{lcccc}
\hline \multirow{2}{*}{ Number } & \multicolumn{4}{c}{ Index } \\
& VV (\%) & VMA (\%) & VFA (\%) & MS (KN) \\
\hline 1 & 6.12 & 14.2 & 56.9 & 9.63 \\
2 & 6.31 & 14.3 & 55.9 & 11.54 \\
3 & 4.32 & 12.5 & 65.4 & 10.66 \\
4 & 4.11 & 13.6 & 69.8 & 11.33 \\
5 & 3.23 & 14.8 & 78.2 & 11.29 \\
6 & 4.66 & 16.3 & 71.4 & 9.79 \\
7 & 5.32 & 13.9 & 61.7 & 11.63 \\
8 & 6.12 & 13.2 & 53.6 & 12.12 \\
9 & 4.33 & 16.9 & 74.4 & 10.35 \\
10 & 2.89 & 14.8 & 80.5 & 10.93 \\
11 & 4.51 & 15.2 & 70.3 & 11.34 \\
12 & 4.38 & 14.1 & 68.9 & 11.62 \\
13 & 3.61 & 13.1 & 72.4 & 10.08 \\
14 & 5.32 & 12.7 & 58.1 & 11.36 \\
15 & 5.15 & 16.2 & 68.2 & 8.53 \\
16 & 4.52 & 14.7 & 69.3 & 9.88 \\
\hline
\end{tabular}

$4.75 \mathrm{~mm}, 0.075 \mathrm{~mm}$, and $9.5 \mathrm{~mm}$. The $2.36 \mathrm{~mm}$ sieve size is the critical factor, and the value of VMA increases by increasing the passing rate of $2.36 \mathrm{~mm}$. Figure 1 (d) shows that the influence sequence of each factor from high to low is $2.36 \mathrm{~mm}, 13.2 \mathrm{~mm}, 4.75 \mathrm{~mm}, 9.5 \mathrm{~mm}$, and $0.075 \mathrm{~mm}$. The medium value of VFA between $65 \%$ and $75 \%$ is used to get the optimal level of each sieve, and the results indicate that the passing rate of $13.2 \mathrm{~mm}$ is $100 \%$, followed by $9.5 \mathrm{~mm}$, $4.74 \mathrm{~mm}, 2.36 \mathrm{~mm}$, and $0.075 \mathrm{~mm}$ with $48 \%, 50 \%, 34 \%$, and $8 \%$, respectively.

\section{Recommended Gradation}

According to the range analysis of orthogonal tests, the sieve of $2.36 \mathrm{~mm}$, as the key factor, has the large effect on Marshall indexes for each gradation scheme, while the sieve of $9.5 \mathrm{~mm}$ has less effect on these indexes. The dense structures of mixtures were formed and analyzed. The orthogonal and experimental analyses were performed to analyze the impact of each factor of volumetric parameters: Marshall stabilities, volume of air voids (VV), voids filled with asphalt (VFA), and voids in the mineral aggregate (VMA). There are two different kinds of AC-13 gradations in the China specification, and the recommended gradation ranges of the asphalt mixtures are shown in Figure 2.

\section{Mixture Design}

On the basis of the recommended gradation and design requirements, the coarse, medium, and fine gradations were designed and grouped. The asphalt content of 5.0\% for preliminary tests was selected and used to perform Marshall comparison tests. Considering the volume parameters and design requirements of mixtures, the coarse gradation was recommended and used as the design gradation in this project. The fluctuation of a base asphalt-aggregate ratio does not exceed $0.3 \%$, and the Marshall tests were conducted at different ratios. The optimum asphalt content (OAC) of the asphalt mixture is $4.8 \%$ from the results (Figure 3 ) of flow value, 
TABLE 10: Range analysis of orthogonal tests.

\begin{tabular}{lccccc}
\hline Index & & \multicolumn{2}{c}{ Range } & \\
& $N_{1}(13.2 \mathrm{~mm})$ & $N_{2}(9.5 \mathrm{~mm})$ & $N_{3}(4.75 \mathrm{~mm})$ & $N_{4}(2.36 \mathrm{~mm})$ & 1.55 \\
VV & 1.19 & 0.5 & 1.04 & 2.03 & 0.88 \\
VMA & 1.6 & 0.85 & 1.28 & 11.95 & 0.95 \\
VFA & 11.53 & 5.08 & 8.23 & 1.27 & 4.75 \\
MS & 1.24 & 0.9 & 0.96 & $0.075 \mathrm{~mm})$ \\
\hline
\end{tabular}

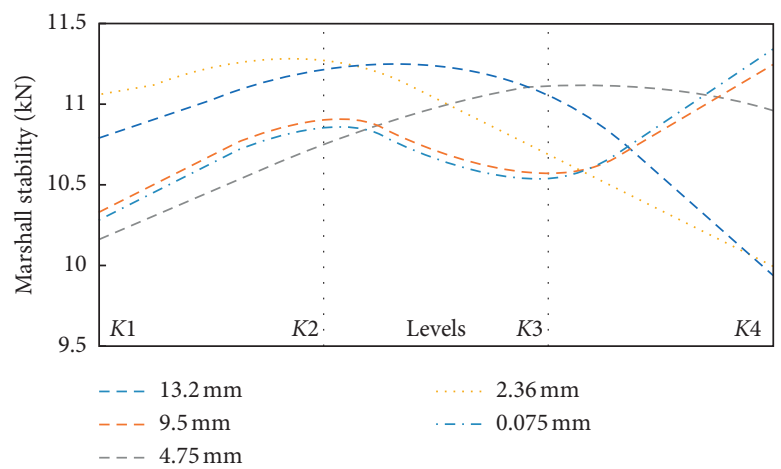

(a)

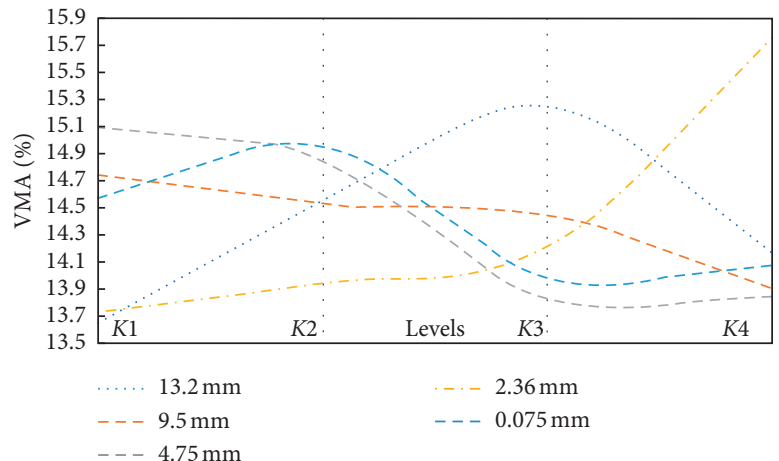

(c)

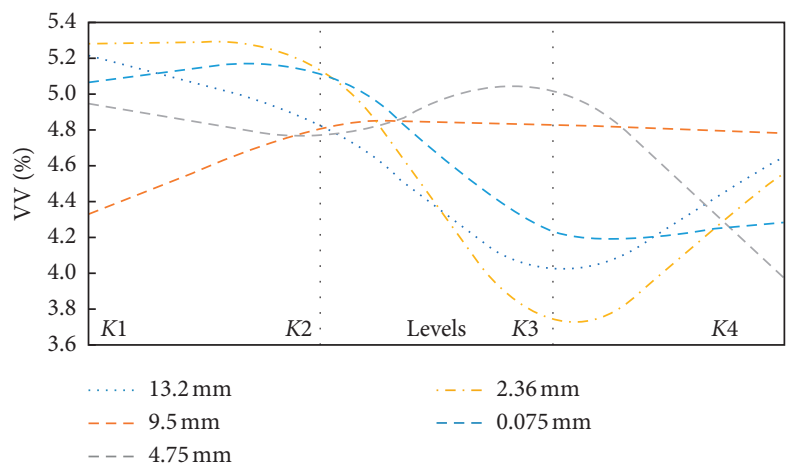

(b)

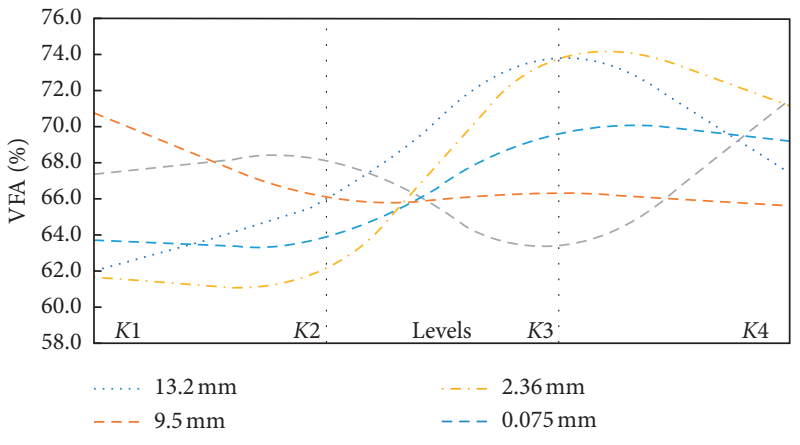

(d)

Figure 1: The Marshall stability, volume of air voids (VV), voids in mineral aggregate (VMA), voids filled with asphalt (VFA)of Orthogonal Tests. (a) Marshall Stability. (b) Volume of air voids (VV). (c) Voids in Mineral Aggregate (VMA). (d) Voids filled With Asphalt (VFA).

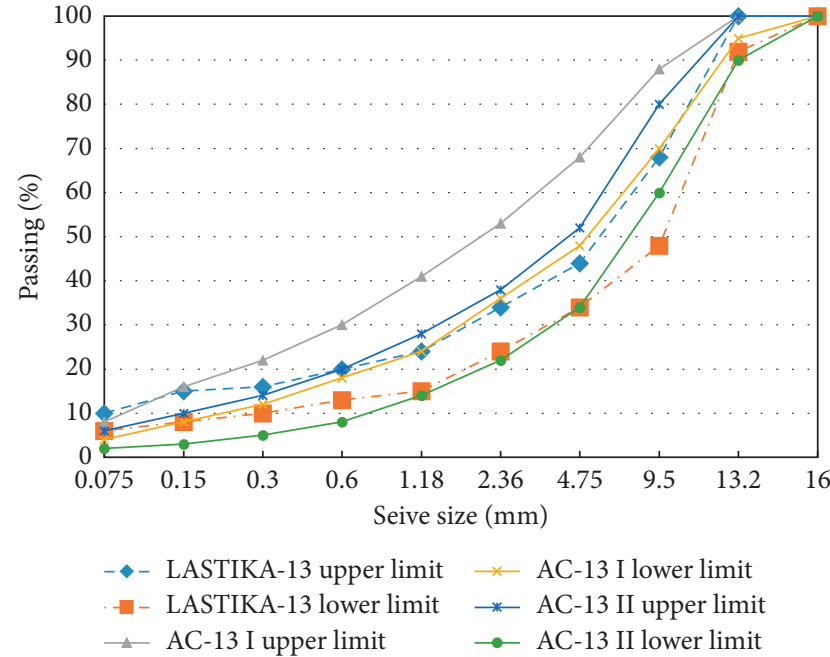

FIgURE 2: Three gradations of asphalt mixtures used in this project. stability, voids filled with asphalt (VFA), voids in the mineral aggregate (VMA), and volume of air voids (VV) based on the China specifications JTG E20-2011, which describes the determination steps of optimum asphalt content or optimum asphalt-aggregate ratio. The asphalt mixture with an AC-13 gradation was designed and mixed in order to further analyze the mixture performance of the recommended gradation LASTIKA-13 for comparisons. The SBS and NRA modified asphalt binders and mixtures were also used to mix with two gradations: LASTIKA-13 and AC-13. The symbols used in this project were explained as follows: the NRA modified asphalt mixture with the gradation AC-13 is named as AC-13-I, and the SBS modified asphalt mixture with the gradation AC-13 is named as AC-13-II.

Three trial asphalt mixtures with different gradations and modifiers were prepared to determine the optimum asphalt content or optimum asphalt-aggregate ratio. The trial mixture test results are shown in Figure 3. Figure 3 shows the mixture 


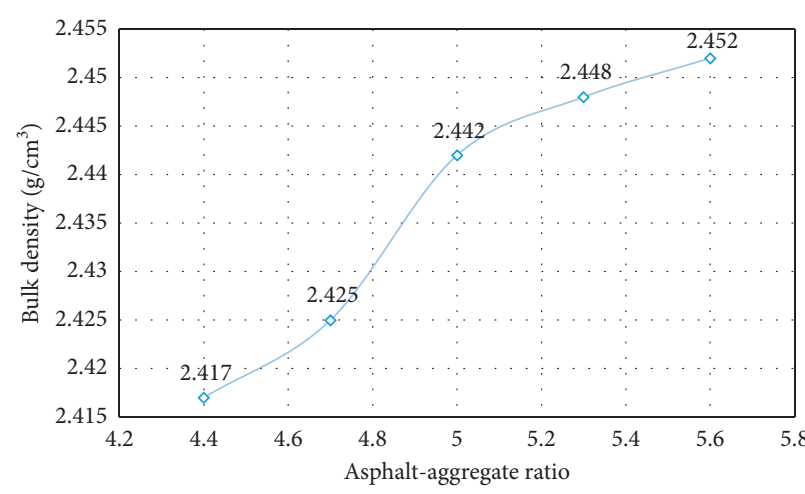

(a)

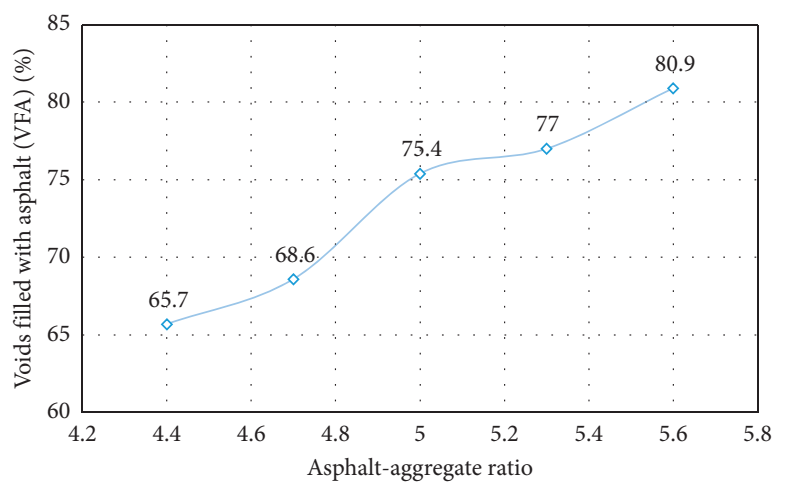

(c)

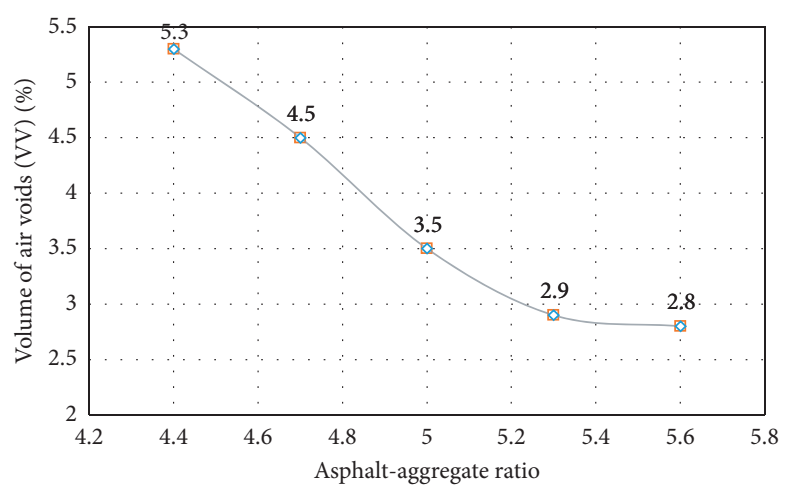

(e)

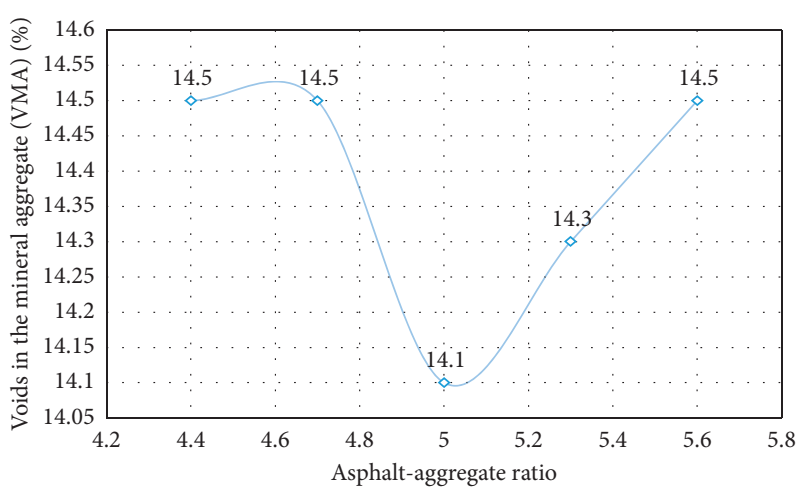

(b)

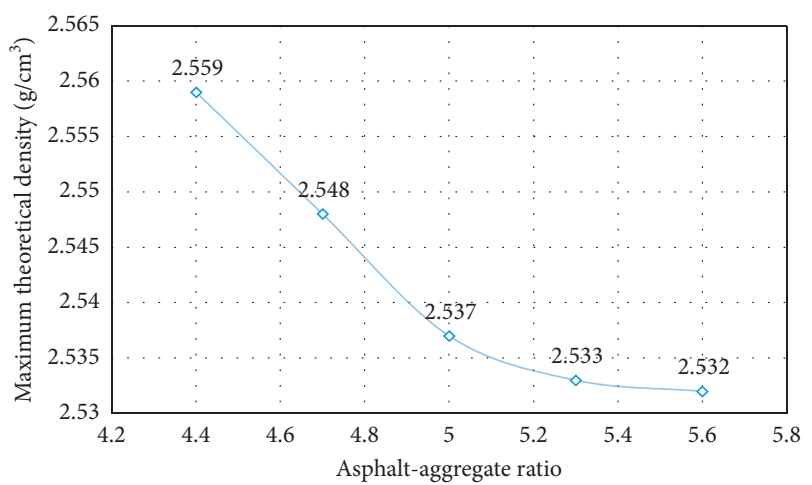

(d)

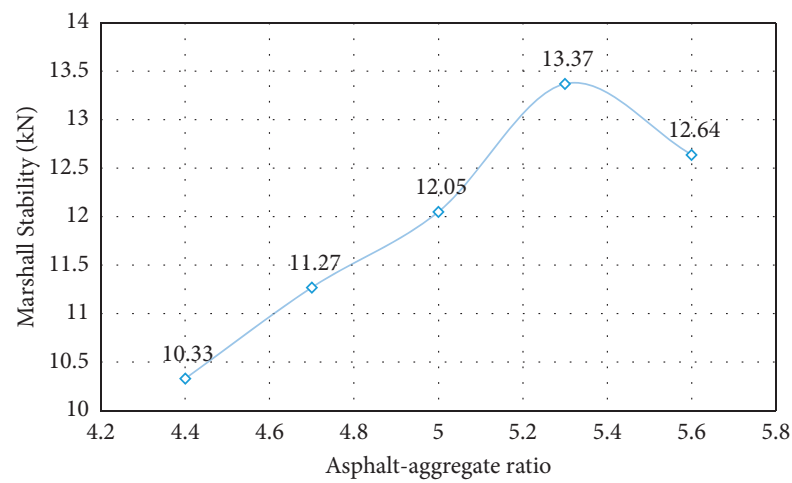

(f)

FIgURE 3: Continued. 


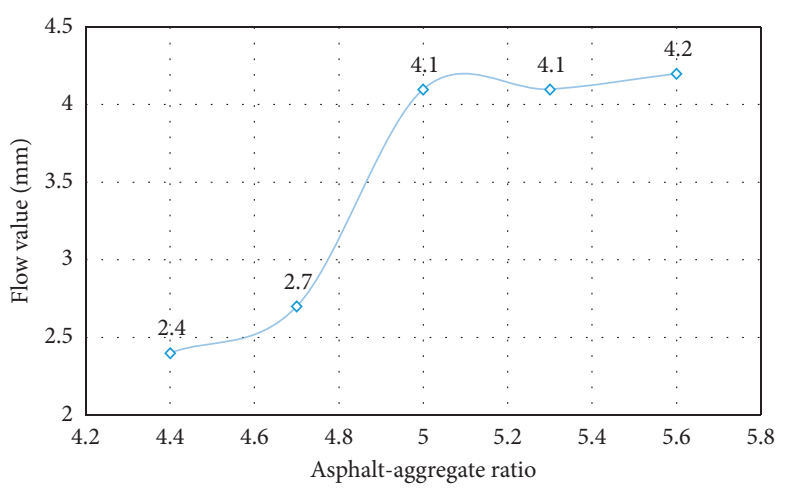

(g)

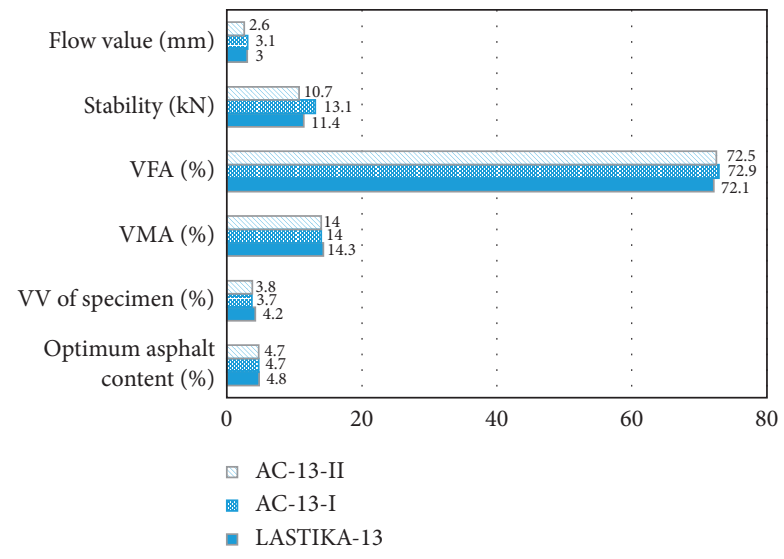

(h)

FIgURE 3: The determination steps of optimum asphalt content or optimum asphalt-aggregate ratio and volumetric parameters of Three asphalt mixtures during the mixture preparation. (a) Bulk density of trial NRA modified asphalt mixtures with the gradation LASTIKA-13. (b) Voids in the mineral aggregate (VMA) of trial NRA modified asphalt mixtures with the gradation LASTIKA-13. (c) Voids filled with asphalt (VFA) of trial NRA modified asphalt mixtures with the gradation LASTIKA-13. (d) Maximum theoretical density of trial NRA modified asphalt mixtures with the gradation LASTIKA-13. (e) Volume of air voids of trial NRA modified asphalt mixtures with the gradation LASTIKA-13. (f) Marshall stability of trial NRA modified asphalt mixtures with the gradation LASTIKA-13. (g) Flow value of trial NRA modified asphalt mixtures with the gradation LASTIKA-13. (h) Summary of trial asphalt mixtures: AC-13-I, AC-13-II, and LASTIKA-13.

results of bulk density, maximum theoretical density, VV, VMA, VFA, Marshall stability, and Flow values. The volumetric parameters of asphalt mixtures with the gradation LASTIKA-13 are shown in Figures 3(a) to 3(g). Figure 3(h) summarized the parameter results of three asphalt mixtures: AC-13-I, AC-13-II, and LASTIKA-13. The VV and VMA of asphalt mixtures AC-13-I and AC-13-II were slightly lower than those of asphalt mixture LASTIKA-13. The volumetric parameters of three asphalt mixtures meet the China specifications JTG E20-2011, and these are reasonable for constructions. The peak/trough points of these parameters were observed, and the optimum asphalt-aggregate ratio (5.0\%) was determined by the trough point of the VMA curve. The optimum asphalt content is different from the optimum asphaltaggregate ratio. Therefore, the optimum asphalt content was around $4.8 \%$ for the asphalt mixture: LASTIKA-13 and these gradations were selected for the mixture performance tests.

\section{Performance of High Viscosity Asphalt Mixtures}

7.1. Antirutting Performances. The rutting tests were employed to conduct a testing comparison on high-temperature performance of mixtures with the gradation of LASTIKA-13, AC-13-I, and AC-13-II. During the tests, a moving vehicle was used to apply the loading on the rutting plate to simulate the effect of compaction, shearing, displacement, and bend. The dynamic stability was defined as the recycle times for per $\mathrm{mm}$ of vertical displacement, when the specimen reaches the stable stage of deformation. The dynamic stability was used to evaluate the deformation resistance of asphalt mixtures under the specified temperatures. The testing temperatures were selected as $50^{\circ} \mathrm{C}, 60^{\circ} \mathrm{C}$, and $70^{\circ} \mathrm{C}$. The test equipment and the test results were plotted in Figures 4 and 5, respectively.
As shown in Figure 5, the dynamic stability of three asphalt mixtures at high temperatures can meet the technical requirements, especially at the temperature of $70^{\circ} \mathrm{C}$, and the dynamic stability of asphalt mixture with the LASTIKA-13 gradation reaches more than 2800 time $/ \mathrm{mm}$. The asphalt mixture with the LASTIKA-13 gradation has a good rutting resistance. When the temperature rises from $50^{\circ} \mathrm{C}$ to $70^{\circ} \mathrm{C}$, the dynamic stability for the asphalt mixture with the LASTIKA-13 decreased from 3550 time/mm to 2900 time/ $\mathrm{mm}$. The decrease rate of dynamic stability in LASTIKA-13 samples is $17.9 \%$, which is less than $24.6 \%$ of AC-13-I samples. The temperature changes have less influence on the mixtures with the LASTIKA-13 gradation. The result indicates that the NRA mixture with the LASTIKA-13 was superior to others in the application in hot and humid areas.

7.2. Low-Temperature Properties. The bending beam tests at low temperature were employed to comprehensively assess the low-temperature cracking of LASTIKA-13, AC-13-I, and AC-13-II mixtures. The dimension of the specimens is $30 \mathrm{~mm} \times 35 \mathrm{~mm} \times 250 \mathrm{~mm}$, as shown in Figure 6. The tests were conducted at the temperatures of $-15^{\circ} \mathrm{C},-10^{\circ} \mathrm{C}$, and $0^{\circ} \mathrm{C}$, respectively. After the specimen was fixed and confined, the initial setting was adopted, and the testing loads were performed. The experimental results are plotted in Figure 7.

In Figure 7, it can be seen from the flexural-tensile data at the temperatures of $0^{\circ} \mathrm{C},-10^{\circ} \mathrm{C}$, and $-15^{\circ} \mathrm{C}$ that the flexuraltensile strength of mixtures with the gradation LASTIKA-13 is stronger than that of AC-13-II and AC-13-I. The flexuraltensile strength of asphalt mixtures is related to the anticracking property at low temperature. The asphalt mixtures with the gradation of LASTIKA-13 have a better cracking resistance. The asphalt mixtures with the gradation of LASTIKA-13 have a larger ultimate strain than others under the 


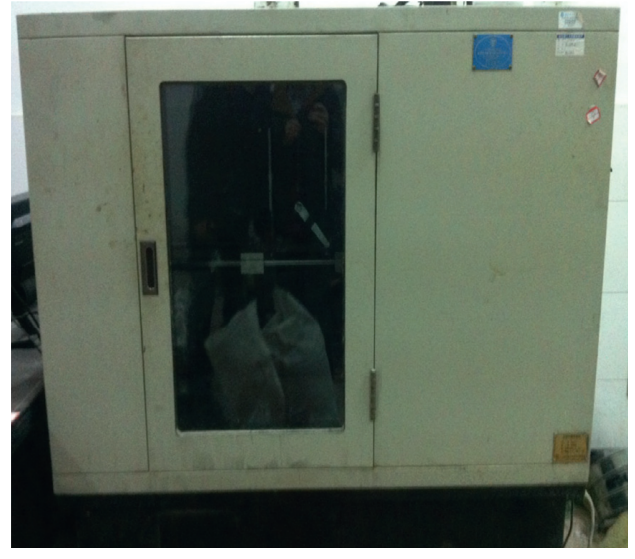

(a)

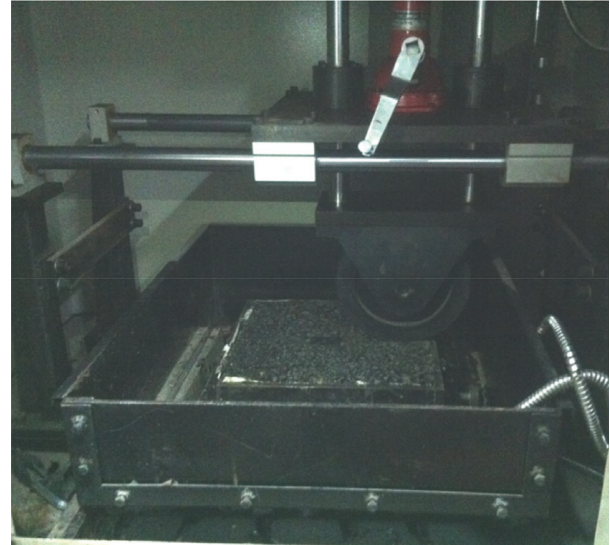

(b)

FiguRE 4: Rutting apparatuses for three asphalt mixtures.

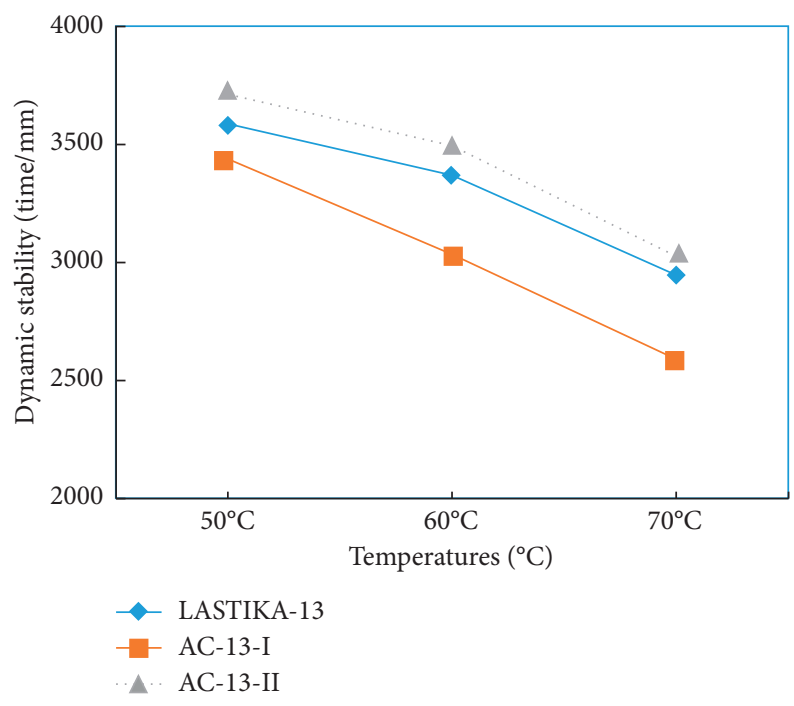

Figure 5: Dynamic stability of asphalt mixtures.

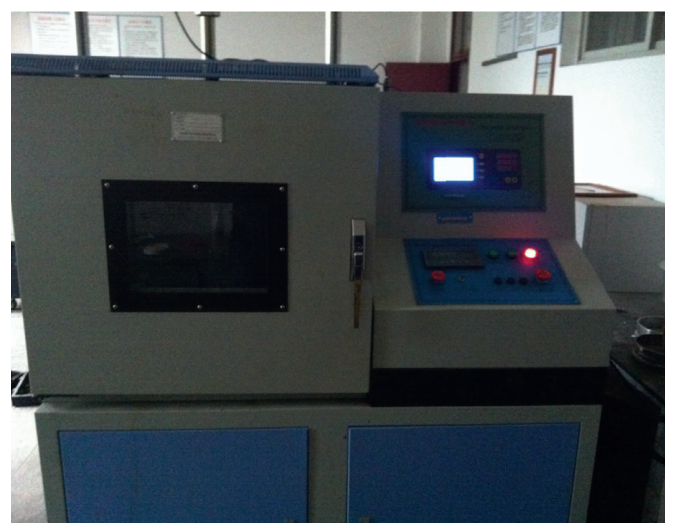

(a)

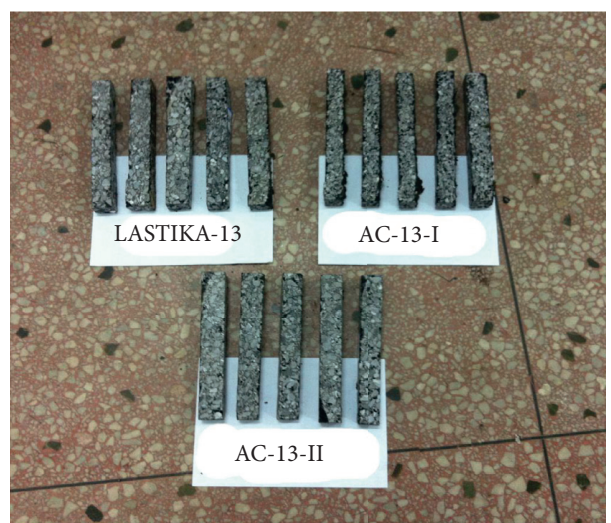

(b)

Figure 6: (a) Testing equipment and (b) beam samples.

same loading conditions. The test results showed that the flexural property of asphalt mixture with the gradation of LASTIKA-13 was superior to other asphalt mixtures, denoting that the proposed HVAM will be more appropriate for the low-temperature condition. In addition, when the temperature decreases from $0^{\circ} \mathrm{C}$ to $-15^{\circ} \mathrm{C}$, the flexural-tensile 


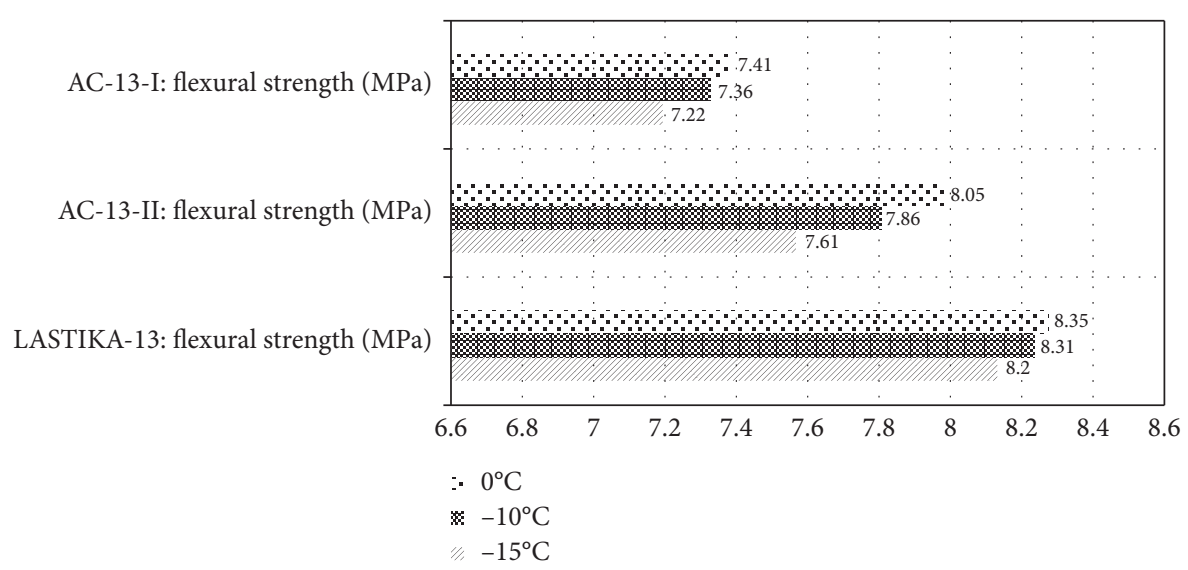

(a)

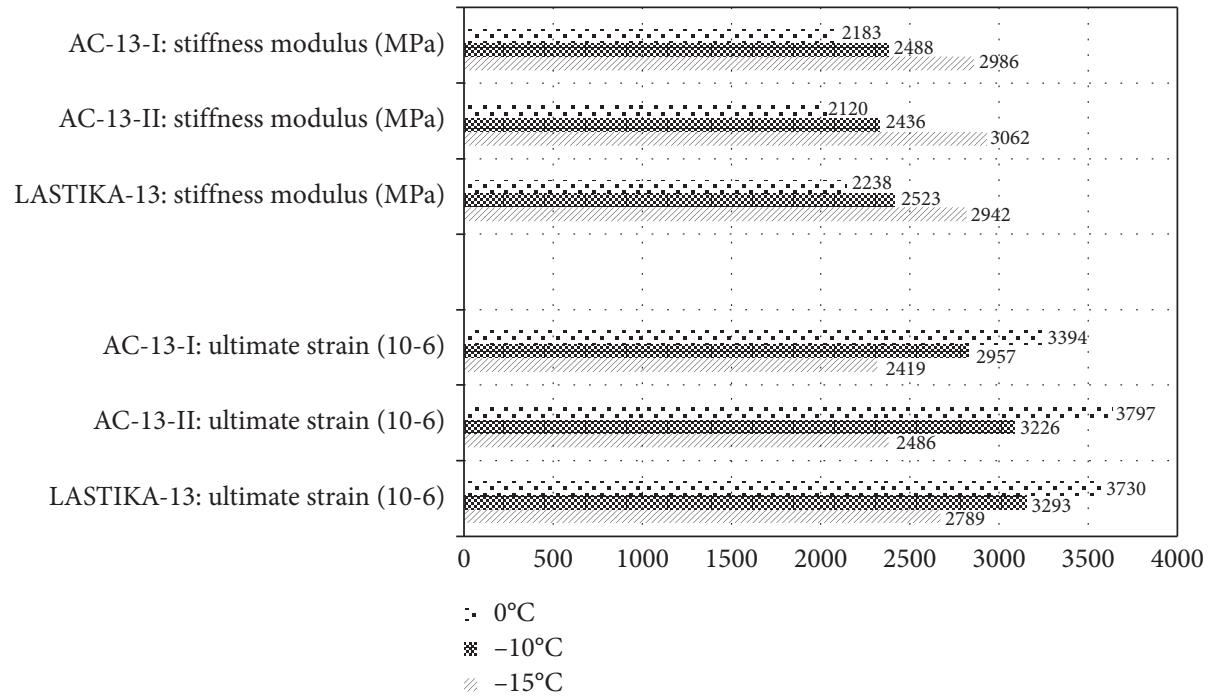

(b)

FIGURE 7: Bending beam test results of asphalt mixtures at different temperatures: (a) The flexural strength of asphalt mixtures with different temperatrues. (b) The stiffness modulus and ultimate strain of asphalt mixtures with different temperatures.

strength of asphalt mixtures with the gradation of LASTIKA13 decreases by $1.7 \%$, which is less than $5.4 \%$ for AC-13-II and $2.5 \%$ for AC-13-I. The decreasing and changing ranges of the ultimate strain in asphalt mixtures with the gradation of LASTIKA-13 are $25.2 \%$, while they are $34.5 \%$ for AC-13-II and $40.3 \%$ for AC-13-I. This means that the strength and deformation of the asphalt mixtures with the gradation of LASTIKA-13 were less affected by temperature compared to others. The low-temperature susceptibility of NRA asphalt mixtures with the gradation of LASTIKA-13 is noticed, and an excellent low-temperature property can be deduced.

7.3. Moisture Stability. The residual stability and freezethaw splitting tests were conducted in accordance with the China specifications. The specimen (Figure 8) was kept under the temperature of $-18^{\circ} \mathrm{C}$ for 24 hours and then tested to determine the splitting tensile strength. The strength was compared with that of the specimen kept under the temperature of $20^{\circ} \mathrm{C}$. The tensile strength ratio (TSR) between the two tested specimens could be used to evaluate the resistance of water damage for asphalt mixtures. For each gradation, four pairs of specimens have been performed to determine the average TSR, and the test results of three kinds of modified asphalt mixtures are shown in Figure 9.

In Figure 9, the TSR of NRA modified asphalt mixtures with the gradation of LASTIKA-13 is $92.1 \%$, and the freezethaw splitting strength of asphalt mixtures with the gradation of LASTIKA-13 is $90.6 \%$. All data of asphalt mixtures satisfy the technical requirements (China Standard, JTG E20-2011), while the NRA asphalt mixtures with the gradation of LASTIKA-13 have a better residual stability. The residual stabilities and freeze-thaw splitting strengths of all asphalt mixtures are higher than $90 \%$. This means that a good resistance to water damage of modified asphalt mixtures can be observed.

7.4. Fatigue Resistance. The fatigue resistance of asphalt mixtures with the gradation of LASTIKA-13, AC-13-I, and AC-13-II was evaluated by Materials Testing System (MTS). 


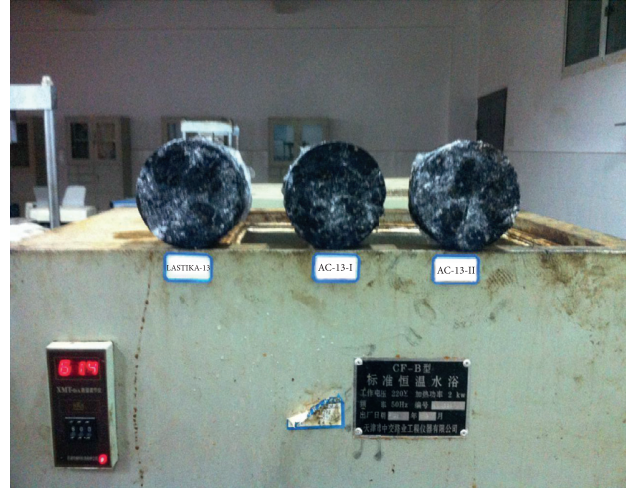

(a)

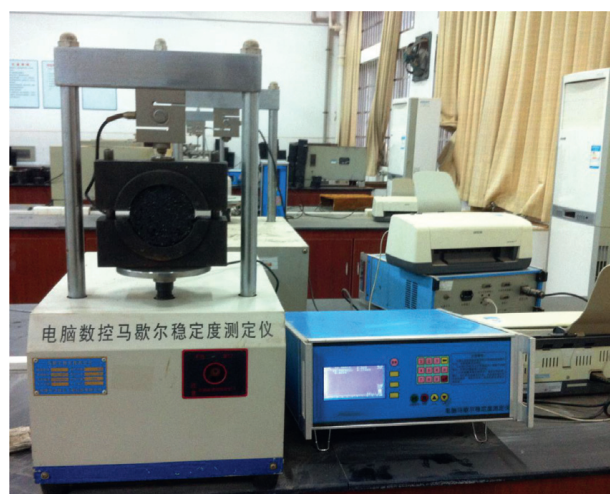

(b)

FIGURE 8: Marshall test instruments under the freeze-thaw conditions.

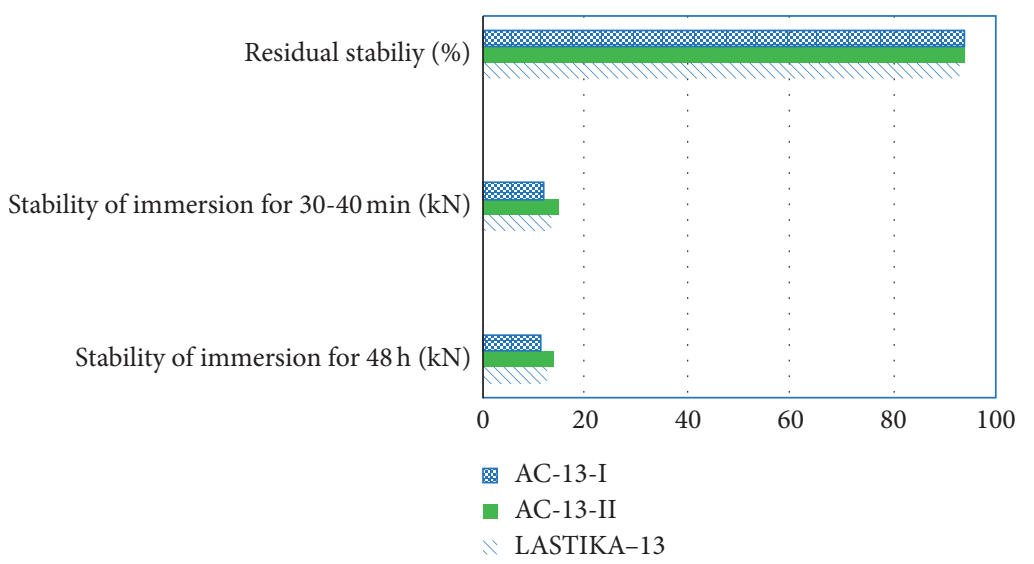

(a)

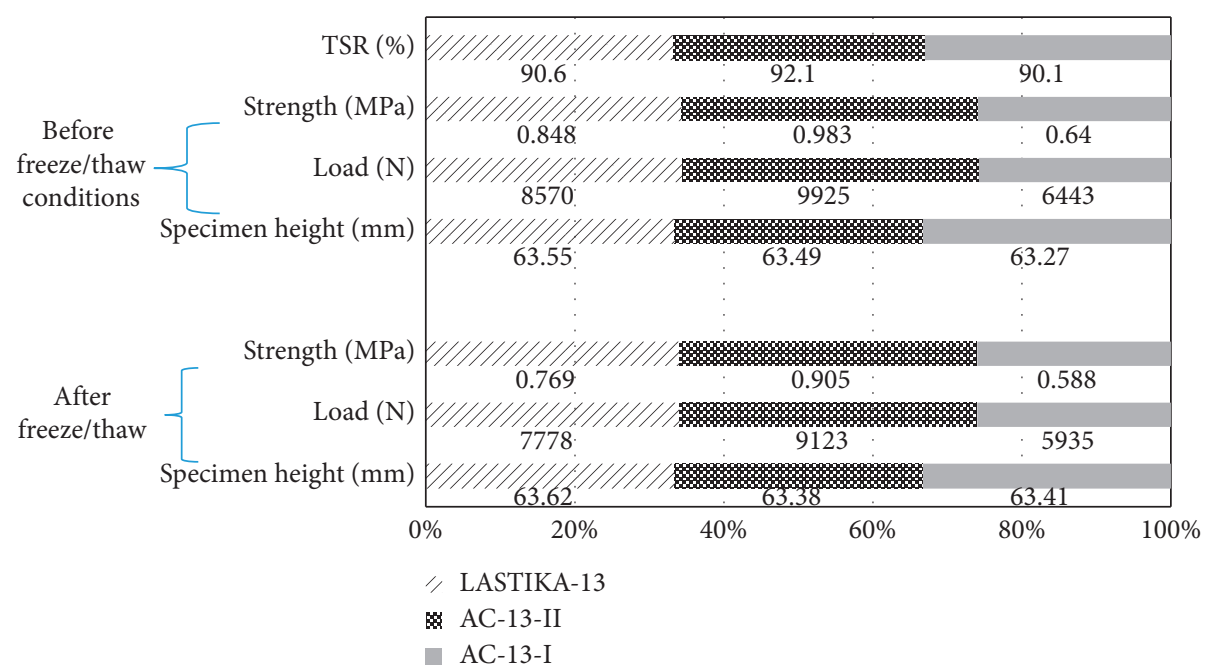

(b)

FIgURE 9: Tensile Strength Ratio (TSR) results of asphalt mixtures: (a) Marshall stability test results of asphalt mixtures. (b) Sample dimensions and loading conditions of asphalt mixtures.

The rutting plate was cut into beam specimen with the dimension of $250 \mathrm{~mm}$ in length and $50 \mathrm{~mm}$ in height and width. Four specimens for each gradation were tested. Dynamic loading with a sine shape and different stress ratios was applied in the experiment, and the stress ratio is defined as the ratio of maximum to the minimum of the loading amplitude. The loading frequency was set as $10 \mathrm{~Hz}$. During the test, the applied loading and flexural stiffness of each 

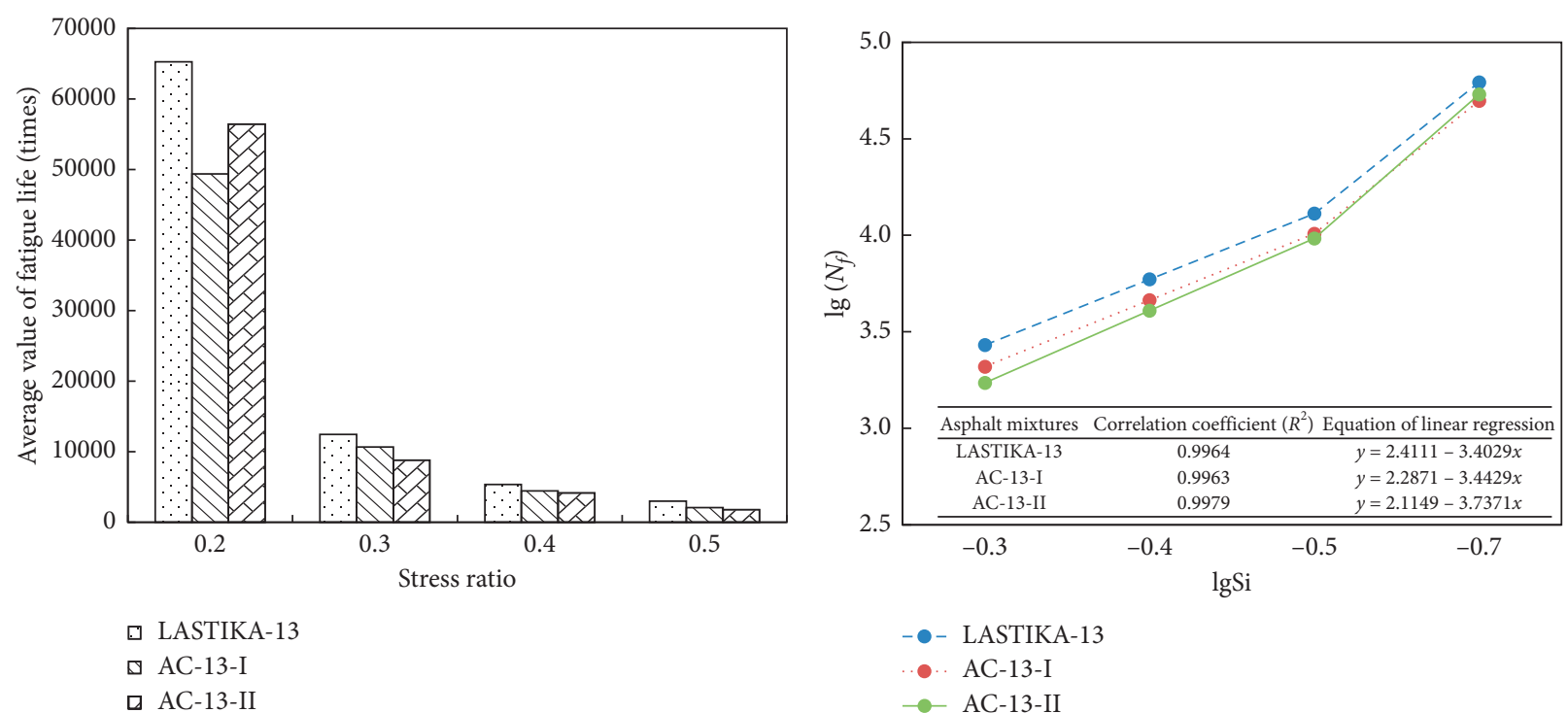

(a)

(b)

\begin{tabular}{cccc}
\hline Asphalt mixtures & Coefficient $\left(R^{2}\right)$ & Linear regression & Asphalt mixtures \\
\hline LASTIKA-13 & 0.9964 & $y=2.4111-3.4029 x$ & LASTIKA-13 \\
AC-13-I & 0.9993 & $y=2.2871-3.4429 x$ & AC-13-I \\
\hline
\end{tabular}

(c)

Figure 10: Fatigue life resistance of asphalt mixtures with different gradations: (a) Fatigue life results of asphalt mixtures with different gradations; (b) Fatigue Life and Linear Regression of Asphalt Mixtures; (c) The linear regression of fatigue life of asphalt mixtures.

loading cycle were recorded. The fatigue life was defined as the number of loading cycles until the stiffness modulus reaches the half of the initial value. The average fatigue life of the asphalt mixture of various gradations is listed in Figure 10.

It can be seen from Figure 10(a) that the fatigue cycle number of asphalt mixtures with LASTIKA-13 gradation was greater than that with AC-13-I and AC-13-II at various stress ratios. The greater fatigue life indicates that the asphalt mixture with the LASTIKA-13 was superior to antifatigue performance and lifespan compared to other asphalt mixtures. The relationship between fatigue life and stress ratio could be characterized by a linear regression in the double logarithmic domain. The linear equation was $\lg N f=$ $k-n \lg S_{i}$, where the $S_{i}$ is the stress ratio, and the absolute value of $n$ represents the slope of curve located at the log-log coordinates. The regress equation parameters were also demonstrated in Figure 10(b). The absolute value $n$ of the asphalt mixtures with the gradation of LASTIKA-13 was 3.40, while it is 3.44 for AC-13-I and 3.74 for AC-13-II. The small slope $n$ means less susceptibility of loadings. Therefore, the NRA asphalt mixtures with the gradation of LASTIKA13 had the slower decrease of fatigue life with the increase of stress ratio, and the influence of loading changes was minimum compared to others.

\section{Conclusions}

The NRA modified asphalt binder was proposed to improve the performance of asphalt mixture. And the NRA modified asphalt mixture with the LASTIKA-13 was prepared and tested in the laboratory to evaluate the performance of proposed HVAM. Based on the comparison with the SBS modified asphalt mixture, the following conclusions can be drawn:

(1) Compared with the conventional SBS modified asphalt binder $[6,15,21,23,32,33]$, the asphalt binder with the content NRA of $15 \%$ showed a relatively better performance, which provides the potential to produce the asphalt mixture with high viscosity performance.

(2) The orthogonal test method was effective in the degradation design of asphalt mixture. The asphalt mixture with the LASTIKA-13 gradation had the excellent high-temperature properties and a better resistance to water damage compared to others.

(3) The proposed HVAM produced with the NRA modifier and LASTIKA-13 gradation was superior to conventional mixtures in the temperature susceptibility and fatigue life performance; in addition, the propose HVAM has a low sensitivity to loading changes.

(4) The good performance of proposed HVAM provides the potential for the application in the high-temperature area, which should be studied in subsequent field construction.

\section{Data Availability}

The data used to support the findings of this study are included within the article. 


\section{Conflicts of Interest}

The authors declare no conflicts of interest.

\section{Authors' Contributions}

Xudong $\mathrm{Hu}$, Sheng Li, and Hui Yao conceived this project and revised the manuscript. Xudong Hu, Hui Yao, Mei Xu, and Dandan Cao wrote the manuscript. Mohd Rosli Mohd Hasan, Cong Duan, and Ran Zhang provided the technical support for this project.

\section{Acknowledgments}

This project was sponsored by National Science Foundation of China (51478052) and Guangdong Science and Technology Department (2013-01-002 and 2013-02). The authors also appreciate the funding support from Beijing Key Laboratory of Traffic Engineering, Beijing University of Technology, under grant no. 2018BJUT-JTJD007 and funding support from Beijing Municipal Commission of Transport (Grant number: 40038003201805).

\section{References}

[1] X. Hu, H. Wang, and H. Wang, "The performance of nanometer $\mathrm{CaCO} 3$ high-viscosity compound modified asphalt," in Proceedings of the 1st International Conference on Transportation Infrastructure and Materials (ICTIM), pp. 201-218, Xi'an, China, July 2016.

[2] L. Li, H. Geng, and Y. Sun, "Simplified viscosity evaluating method of high viscosity asphalt binders," Materials and Structures, vol. 48, no. 7, pp. 2147-2156, 2015.

[3] L.-t. Geng, Q. Xu, R.-b. Ren, L.-z. Wang, X.-1. Yang, and X.-y. Wang, "Performance research of high-viscosity asphalt mixture as deck-paving materials for steel bridges," Road Materials and Pavement Design, vol. 18, no. 1, pp. 208-220, 2017.

[4] E. Bocci, A. Graziani, and F. Canestrari, "Mechanical 3D characterization of epoxy asphalt concrete for pavement layers of orthotropic steel decks," Construction and Building Materials, vol. 79, pp. 145-152, 2015.

[5] Z. Qian, C. Chen, C. Jiang, and A. d. F. Smit, "Development of a lightweight epoxy asphalt mixture for bridge decks," Construction and Building Materials, vol. 48, pp. 516-520, 2013.

[6] R. Zhang, H. Wang, J. Gao, Z. You, and X. Yang, "High temperature performance of SBS modified bio-asphalt," Construction and Building Materials, vol. 144, pp. 99-105, 2017.

[7] F. Zhang and C. Hu, "Preparation and properties of high viscosity modified asphalt," Polymer Composites, vol. 38, no. 5, pp. 936-946, 2017.

[8] H. Yao, Z. You, L. Li et al., "Rheological properties and chemical analysis of nanoclay and carbon microfiber modified asphalt with Fourier transform infrared spectroscopy," Construction and Building Materials, vol. 38, pp. 327-337, 2013.

[9] H. Yao, Z. You, L. Li et al., "Evaluation of asphalt blended with low percentage of carbon micro-fiber and nanoclay," Journal of Testing and Evaluation, vol. 41, no. 2, pp. 1-11, 2013.

[10] H. Yao, Z. You, L. Li et al., "Rheological properties and chemical bonding of asphalt modified with nanosilica,"
Journal of Materials in Civil Engineering, vol. 25, no. 11, pp. 1619-1630, 2013.

[11] X. Shu and B. Huang, "Recycling of waste tire rubber in asphalt and portland cement concrete: an overview," Construction and Building Materials, vol. 67, pp. 217-224, 2014.

[12] H. Wang, Z. Dang, L. Li, and Z. You, "Analysis on fatigue crack growth laws for crumb rubber modified (CRM) asphalt mixture," Construction and Building Materials, vol. 47, pp. 1342-1349, 2013.

[13] H. Wang, Z. Dang, Z. You, and D. Cao, "Effect of warm mixture asphalt (WMA) additives on high failure temperature properties for crumb rubber modified (CRM) binders," Construction and Building Materials, vol. 35, pp. 281-288, 2012.

[14] H. Asli, E. Ahmadinia, M. Zargar, and M. R. Karim, "Investigation on physical properties of waste cooking oil-rejuvenated bitumen binder," Construction and Building Materials, vol. 37, pp. 398-405, 2012.

[15] L. Xiang, J. Cheng, and S. Kang, "Thermal oxidative aging mechanism of crumb rubber/SBS composite modified asphalt," Construction and Building Materials, vol. 75, pp. 169-175, 2015.

[16] H. Yao, Z. You, L. Li et al., "Performance of asphalt binder blended with non-modified and polymer-modified nanoclay," Construction and Building Materials, vol. 35, pp. 159-170, 2012.

[17] H. Yao, Q. Dai, and Z. You, "Chemo-physical analysis and molecular dynamics (MD) simulation of moisture susceptibility of nano hydrated lime modified asphalt mixtures," Construction and Building Materials, vol. 101, no. 1, pp. 536-547, 2015.

[18] Q. Yang, X. Li, L. Zhang et al., "Performance evaluation of bitumen with a homogeneous dispersion of carbon nanotubes," Carbon, vol. 158, pp. 465-471, 2020.

[19] K. Yan, M. Zhang, L. You, S. Wu, and H. Ji, "Performance and optimization of castor beans-based bio-asphalt and European rock-asphalt modified asphalt binder," Construction and Building Materials, vol. 240, p. 117951, 2020.

[20] J. Li, S. Duan, Y. Muhammad et al., "Microwave assisted fabrication of polymethyl methacrylate-graphene composite nanoparticles applied for the preparation of SBS modified asphalt with enhanced high temperature performance," Polymer Testing, vol. 85, p. 106388, 2020.

[21] C. Qian, W. Fan, G. Yang, L. Han, B. Xing, and X. Lv, "Influence of crumb rubber particle size and SBS structure on properties of CR/SBS composite modified asphalt," Construction and Building Materials, vol. 235, p. 117517, 2020.

[22] X. Jin, N. Guo, Z. You, L. Wang, Y. Wen, and Y. Tan, "Rheological properties and micro-characteristics of polyurethane composite modified asphalt," Construction and Building Materials, vol. 234, p. 117395, 2020.

[23] F. Ye, W. Yin, H. Lu, and Y. Dong, "Property improvement of Nano-Montmorillonite/SBS modified asphalt binder by naphthenic oil," Construction and Building Materials, vol. 243, p. 118200, 2020.

[24] S. Duan, Y. Muhammad, J. Li et al., "Enhancing effect of microalgae biodiesel incorporation on the performance of crumb Rubber/SBS modified asphalt," Journal of Cleaner Production, vol. 237, p. 117725, 2019.

[25] C. Qian, W. Fan, F. Ren, X. Lv, and B. Xing, "Influence of polyphosphoric acid (PPA) on properties of crumb rubber (CR) modified asphalt," Construction and Building Materials, vol. 227, p. 117094, 2019.

[26] X. Hu, "Performance evaluation of superflex modified thin asphalt overlay," in Climatic Effects on Pavement and 
Geotechnical InfrastructureAmerican Society of Civil Engineers, Fairbanks, AK, USA, 2013.

[27] M. Wang, The Study on Performance of Superflex Asphalt and Mixture, Chongqing Jiaotong University, Chongqing, China, 2010.

[28] H. Wang, L. Chen, and H. Wang, "Performance of superflex modified asphalt mixture," Road and Transportation, vol. 40, pp. 89-92, 2013.

[29] Y. Sun, Y. Luo, and D. Jia, "Preparation and properties of natural rubber nanocomposites with solid-state organomodified montmorillonite," Journal of Applied Polymer Science, vol. 107, no. 5, pp. 2786-2792, 2008.

[30] F. Dong, W. Fan, G. Yang et al., "Dispersion of SBS and its influence on the performance of SBS modified asphalt," Journal of Testing and Evaluation, vol. 42, no. 5, pp. 10731080, 2014.

[31] C. R. Rao, "Factorial experiments derivable from combinatorial arrangements of arrays," Supplement to the Journal of the Royal Statistical Society, vol. 9, no. 1, pp. 128-139, 1947.

[32] R. Zhang, H. Wang, Z. You, X. Jiang, and X. Yang, "Optimization of bio-asphalt using bio-oil and distilled water," Journal of Cleaner Production, vol. 165, pp. 281-289, 2017.

[33] P. Du, Z. Chen, and H. Zhang, "Rheological and aging behaviors of base and SBS modified asphalt with thermochromic microcapsule," Construction and Building Materials, vol. 200, pp. 1-9, 2019. 